\title{
Financial Development and the Sensitivity of Stock Markets to External Influences ${ }^{1}$
}

\author{
Harris Dellas \\ Martin K. Hess \\ VWI, University of Bern Studienzentrum Gerzensee and \\ University of Bern
}

June 21, 2000

\footnotetext{
${ }^{1}$ Harris Dellas, VWI, University of Bern, Gesellschaftsstrasse 49, CH-3012 Bern, Harris.Dellas@vwi.unibe.ch, http://www-vwi.unibe.ch/amakro/dellas_e.htm. Martin K. Hess, Studienzentrum Gerzensee, CH-3115 Gerzensee, mhess@szgerzensee.ch, http://www.szgerzensee.ch/hess.
} 


\begin{abstract}
We investigate how the relative contribution of external factors to stock price movements varies with the degree of financial development. We find that financial development makes stock markets more susceptible to external influences (both financial and macroeconomic). Interestingly, this effect is present even after having accounted for capital controls and international trade effects.
\end{abstract}

JEL Classifications: F4, G1, O1

Keywords: Financial Development, Stock Markets, External Influences 
The recent pace of international economic integration has been unprecedented. Trade in goods and services has grown faster than output and it has been accompanied by large capital movements both within the industrial countries and across developed and less developed countries. Financial liberalization has accelerated. A frequently asked question is whether increased globalization will translate into stronger comovements of national economic activity and also increase countries' susceptibility to external factors ${ }^{1}$.

The objective of this paper is twofold. First, to calculate the relative importance of domestic and foreign influences on domestic stock prices. Unlike existing financial studies that have been primarily concerned with stock price links only (essentially one factor models), we include several additional domestic and foreign determinants of stock returns. Unlike existing macroeconomic studies that have used a broader set of variables but have restricted themselves to a small number of industrial countries (for instance, Canova and de Nicoló, 1997), we analyze the behavior of a large, diverse group of countries. This allows us to fulfill our second objective, which is to examine whether and how the sensitivity of domestic returns to external shocks varies systematically with a country's level of financial development. This is important as policymakers in less developed countries often express reservations about being "hostage" to the world capital markets. It is also important from an international portfolio selection point of view, as the answer to this question determines how much portfolio insurance can be gained by acquiring equity in less financially developed countries.

Our approach follows closely Canova and De Nicoló (1997). We estimate two country VARs, pairing the country under consideration with a country that represents the main source of external influences. The latter is the US but we have also used Japan or Germany depending on the region. The VARs include measures of economic activity, inflation, interest rates, stock prices and the exchange rate. After estimating the VARs, we use the resulting variance decompositions to form a measure of domestic and foreign influences on the domestic stock prices. In general, the contribution of external factors ranges from $10.2 \%$ to $66.8 \%$ with an average value of $30.0 \%$. We then regress these measures against various indexes of financial development in order to evaluate the role of the latter in the transmission of external shocks to domestic stock prices. In particular, we focus on financial intermediation measures taken from Levine, Loyaza and Beck (1999) and the size of the stock market relative to GDP. We find that financial development is associated with greater sensitivity to foreign shocks. And that this remains the case even after accounting for international trade effects and capital controls. Our results are consistent with Harvey (1995) who argues that local factors play a more important role in emerging markets than in developed markets. They are also in line with Rouwenhorst (1999) who finds that global risk factors are unable to explain the

\footnotetext{
${ }^{1}$ Dellas and Canova (1993) have examined trade integration and macroeconomic interdependence. They find that stronger trade links have not led to greater international business cycle synchronization. The relationship between financial integration and macroeconomic interdependence has not yet been investigated systematically (see Dellas and Hess, 2000).
} 
mean returns of the emerging market return factors, and with Bekaert and Harvey (1997) who show that the correlation between stock returns increases as a result of financial liberalization.

The rest of the paper is organized as follows. Section 1 sketches the relevant theoretical considerations for the assessment of the linkage between a financial market's development and its susceptibility to foreign influences. Section 2 presents the empirical models providing integration and development indicators. Section 3 displays the main findings for a large cross-section of countries. Section 4 concludes.

\section{Theory}

There are two important channels linking the stage of financial development to international economic integration: capital mobility and international trade.

Financial backwardness usually goes hand in hand with official restrictions on capital mobility. Financially developed countries typically impose few restrictions on the flows of capital and as a result they are more closely linked and hence more susceptible to external developments. Moreover, countries with poorly developed financial systems are a less hospitable host for international capital as they lack the institutional infrastructure needed to make profitable use of capital. For instance, the stock markets operate inefficiently (thin markets with rampant inside trading), government regulations are cumbersome and often arbitrary and so on. At the same time, the local financial institutions often lack the expertise required to promote international portfolio diversification on behalf of their domestic clients. Consequently, both inflows and outflows of capital are effectively discouraged. A further argument for the observed capital immobility towards emerging financial markets is put forward by Razin, Sadka and Yuen (1999) who emphasize informational problems. Adverse selection and moral hazard problems due to the lack of regulation and disclosure rules hinder international investment and may be behind the lack of real rates of return equalization. Finally, the existence of political risk is a deterrent to capital mobility.

International trade provides a second channel and involves two mechanisms. First, financially advanced countries (the rich) tend to trade more. A larger degree of openness increases the sensitivity to foreign shocks inducing a positive association between financial development and international financial interdependence.

The second mechanism operates through the effects of trade on the structure of production. Helpman and Razin (1978) note that if a country without a well functioning financial market cannot diversify domestic production risks through international asset trade, it may have to do so by selecting a more diversified production structure. Thus, financial backwardness implies a domestic production structure that is more similar to that in the rest of the world. In the presence of important industry specific shocks this leads to a positive covariation between domestic and world economic activity. The development of financial markets then is accompanied by greater production specialization and hence a smaller correlation in movements in economic activity and stock markets across countries (Dellas 
and Hess, 2000). Financial development and correlation of stock returns move in opposite directions.

This argument is based on the traditional theory of trade and is rather static in nature as it ignores the process of income convergence across countries. If income convergence is followed by convergence in economic structure (for instance, similar factor endowments), as manifested in intraindustry trade patterns, then economic and financial- development implies that a country becomes more like the advanced countries. In such a case one should expect a positive relationship between the stage of economic development and the degree of susceptibility to foreign shocks.

The preceding discussion seems to suggest the existence of a theoretical presumption of a positive link between financial development and financial integration. Nevertheless, there exist legitimate theoretical reasons for observing a negative link (namely, the traditional trade theory). This ambiguity is the source of value added of the empirical analysis that follows.

\section{Empirical analysis}

\subsection{Measures of Financial Market Integration}

The first task is to construct a measure of the sensitivity of domestic returns to external influences (financial integration) ${ }^{2}$. Several indicators of financial (stock) market integration exist in the literature. Bekaert and Harvey (1995) construct one by formulating a Capital Asset Pricing Model in terms of a Markov regime switching model. They postulate that the expected rate of return on a stock $A$ in country $i$ is a function of its comovement with the stock market:

$$
E_{t-1}\left[r_{i, t}^{A}\right]=\lambda_{t-1} \operatorname{cov}_{t-1}\left[r_{i, t}^{A}, r_{t}\right]
$$

In a perfectly integrated world, the market return is measured by the return on the world stock market $r_{w, t}$, whereas under perfect segregation by the domestic market return $r_{i, t}$. Aggregating across all assets and reformulating this equation as a discrete state model yields:

$$
E_{t-1}\left[r_{i, t}\right]=\phi_{i, t-1} \lambda_{t-1} \operatorname{cov}_{t-1}\left[r_{i, t}, r_{w, t}\right]+\left(1-\phi_{i, t-1}\right) \lambda_{t-1} \operatorname{var}_{t-1}\left[r_{i, t}\right]
$$

The estimated transition probability $\widehat{\phi}_{i, t-1}$ indicates then the degree of integration of the local market with the world stock market.

An alternative measure is proposed by Ammer and Mei (1996) who use the correlation between the domestic and foreign stock return innovations.

The problem with these two measures is their incompleteness, namely their not taking into account additional foreign influences on the domestic stock markets.

\footnotetext{
${ }^{2}$ Throughout the paper we identify international financial integration with a country's financial markets' susceptibility to external shocks. This does not take into account the fact that two markets may move in the same way because of other reasons (for instance, the adoption of similar policies) even in the absence of financial integration.
} 
Economic integration can have unidirectional effects on the domestic stock markets. For example, economic expansion in the US that translates into an increase in the demand for US imports from Chile may have a negligible effect on the US stock market but a large impact on the Chilean market. In order to allow for this possibility we suggest an alternative measure of integration which contains both financial and macroeconomic influences. Our measure relies on variance decompositions generated by two country vector autoregressive (VAR) models. Such models can be useful for constructing measures of international integration as they capture nicely the properties of the international transmission of macroeconomic and financial disturbances.

Let $\mathbf{y}_{t}$ be an $(N \times 1)$ vector containing foreign and domestic variables regressed against $p$ lagged values of itself

$$
\mathbf{y}_{t}=\mathbf{c}+\Phi_{1} \mathbf{y}_{t-1}+\Phi_{2} \mathbf{y}_{t-2}+\ldots+\Phi_{p} \mathbf{y}_{t-p}+\mathbf{e}_{t}
$$

where $\mathbf{e}_{t} \sim \operatorname{Niid}(\mathbf{0}, \Sigma)$. The corresponding vector moving average (VMA) representation for a stationary $\mathbf{y}_{t}$ is

$$
\mathbf{y}_{t}=\Pi(L) \mathbf{c}+\Pi(L) \mathbf{e}_{t}
$$

where $\Pi(L)=\left(\mathbf{I}_{N}-\Phi(L)\right)^{-1}$ and $L$ is a lag operator.

In order to examine the transmission properties of a structural shock, we apply a standard recursive structure to the estimated reduced form model (3). Since $\Sigma$ is symmetric and positive definite, the Choleski decomposition ${ }^{3}$ factorizes the covariance matrix $\Sigma$ into $\mathbf{P} \mathbf{P}^{\prime}$ such that $\mathbf{P}$ is a lower triangular matrix. Appropriate premultiplication of $\mathbf{e}_{\mathbf{t}}$ orthogonalizes the error terms. The Wold causal chain representation of the structural VMA is therefore

$$
\begin{aligned}
\mathbf{y}_{t} & =\Pi(\mathbf{L}) \mathbf{P} \mathbf{P}^{-1} \mathbf{c}+\Pi(\mathbf{L}) \mathbf{P} \mathbf{P}^{-1} \mathbf{e}_{\mathbf{t}} \\
& =\boldsymbol{\mu}+\mathbf{C}(\mathbf{L}) \varepsilon_{t}
\end{aligned}
$$

where $\mathbf{C}(\mathbf{L})=\Pi(\mathbf{L}) \mathbf{P}, \boldsymbol{\varepsilon}_{t}=\mathbf{P}^{-1} \mathbf{e}_{\mathbf{t}}, \boldsymbol{\varepsilon}_{t} \sim \operatorname{Niid}\left(\mathbf{0}, \mathbf{I}_{N}\right)$ and $\boldsymbol{\mu}$ is a constant. Since the residuals $\varepsilon_{t}$ are orthogonal to each other, this recursive identification makes it possible to investigate responses to innovations to each of the endogenous variables in $\mathbf{y}_{t}$.

The element $C_{i j, k}$ of the coefficient matrix $\mathbf{C}_{k}$ in the $\operatorname{VMA}(\infty)$ equation (6) represents the impact of a one-unit innovation in variable $j$ on variable $y_{i t}, k$ periods back in time. The variance decomposition $z_{i j, k}$ displays what fraction of the $k$-step ahead forecast error variance for $y_{i t+k \mid t}$ is attributed to the orthogonalized shocks

\footnotetext{
${ }^{3}$ This approach is used often but it is criticized for being somewhat arbitrary because the ordering of the variables is intransitive. If however, the off-diagonal elements of the covariance matrix $\Sigma$ only contains small values the ordering is not likely to be important. Moreover, for our purpose of comparing a large number of different countries, it is an advantage to have one single identification scheme instead of having different restrictions for each of them.
} 
$\varepsilon_{j t}$. Squaring the expectation of the forecast error $y_{i t+k}-y_{i t+k \mid t}=\sum_{j=1}^{N} \sum_{l=0}^{k-1} C_{i j, l} \varepsilon_{j t-l}$ yields the total variance. The estimator

$$
z_{i j, k}=\frac{\sum_{l=0}^{k-1} C_{i j, l}^{2}}{\sum_{j=1}^{N} \sum_{l=0}^{k-1} C_{i j, l}^{2}}
$$

hence represents the sensitivity of variable $i$ to an innovation in variable $j$, which compared with figures of other variables provides an idea of the relative importance of those shocks.

Our measure of integration relies on the decomposition of variance into external and domestic sources. In particular, we take the sum of the shares of all foreign innovations $z_{f}=\sum_{j \in f} z_{i j, k}$ to the $k$-step forecast error variance as a measure of the sensitivity of the domestic stock market to foreign influences $f$. This measure is more general than those used in the financial literature. It is also easy to calculate and quite flexible. By setting $z_{f}=z_{i i_{f}, k}$, where $i_{f}$ represents the foreign stock market, an alternative stock market integration measure arises which is similar to those discussed above.

In our empirical analysis, we capture foreign influences (and hence integration) with one of the two indicators. The first variable takes into account the contribution of all the foreign variables included in the two-country VARs whereas the second variable is a narrow measure for the influence of the foreign stock market.

\subsection{Measures of financial development}

The level of financial development is difficult to calculate. While different measures have been suggested in the empirical literature, we adopt the ones suggested by King and Levine (1993) as they are the most commonly used (mostly in the context of financial development and economic growth). In particular, we rely on the variables constructed by Levine, Loyaza and Beck (1999) who refine the original King-Levine indicators in a large cross-country study. These authors express financial market development in terms of competitive structure and the size of the financial intermediation sector. The competitive structure is expressed by the ratio of commercial bank assets divided by total bank assets (commercial plus central bank assets) (ccb) and reflects the idea that commercial banks are relatively more efficient in managing customer savings. The size of the market is simply calculated as liquid liabilities (currency plus demand and interest-bearing liabilities of banks and nonbank financial intermediaries) divided by GDP (lly) whereas the credits by commercial banks and other institutions to the private sector divided by GDP $(p c)$ is a mixture of both. In addition, we also use an equity market based financial development measure (eqv) which is the ratio of the total value of stocks traded divided by GDP. 


\subsection{The VAR model}

The VARs are estimated using two alternative vectors $\mathbf{y}_{t}^{A}=\left(y^{f}, \pi^{f}, i^{f}, r^{f}, q, y^{d}, \pi^{d}, i^{d}, r^{d}\right)^{\prime}$ and $\mathbf{y}_{t}^{B}=\left(y^{f}, i^{f}, r^{f}, y^{d}, i^{d}, r^{d}\right)^{\prime}$ in which superscripts $d$ and $f$ denote domestic and foreign variables, respectively. The variables included are quarterly observations of GDP $y$, inflation $\pi$, the short term interest rate $i$ as an indicator of monetary policy, stock market returns $r$ and the exchange rate, $q$. As quarterly GDP figures are not available for all countries in the sample, we interpolate to quarterly frequency following the method of Cuche and Hess (1999) ${ }^{4}$.

The variables of each country under consideration are paired with each one of the three foreign countries, namely Germany, Japan and the United States. To assess regional integration, we then divide the world into the three regions America, Europe and Africa, and Pacific Basin, of which we take the three countries as representative economies. The ordering in the vector assumes that domestic variables are contemporaneously endogenous to the foreign variables. Unlike other VAR models, we assume that stock returns are endogenous to all other variables ${ }^{5}$.

We first run the VARs -with 1, 2 and 4 lags- and then use the variance decomposition to calculate the two measures of sensitivity $z_{f}=z_{r^{d} r^{f}, k}$ and $z_{f}=\sum_{j \in f} z_{r^{d} j, k}^{6}$, with $k=12$. The sample consists of 42 countries and it extends from 1980.1-1998.4. However, many countries have shorter time series. In those cases, the sensitivity measure results from a VAR with the maximum number of observations available ${ }^{7}$.

\section{The Results}

Table 1 provides summary statistics on the VAR-based sensitivity measures, on the financial development measures and on the control variables for 42 the countries listed. There is considerable variation across the countries in all measures.

Table 1 : Statistical Properties of the Data

The correlation between the development measures are clearly positive such that we can expect that the dependence of the financial sensitivity to the stage of the financial sector is robust with respect to the choice of the variables. The correlations of the development and the control variables have the expected sign.

\footnotetext{
${ }^{4}$ Cuche and Hess (1999) identify the most suitable model for the interpolation of Swiss GDP. In this paper, we apply the same setup to the interpolated series of all countries (see appendix).

${ }^{5}$ Alternative orderings, such as ordering the macroeconomic variables of both countries above the financial variables did not make any difference for the results.

${ }^{6}$ We calculate the broader integration measure with and without the contribution of the exchange rate. As in Canova and De Nicoló (1997) and other studies, shocks originating in the foreign exchange market have little impact on stock returns and therefore the difference is negligible.

${ }^{7}$ For data availability reasons, a large number of countries had to be eliminated. In particular, most Eastern European countries could not be included.
} 
It is positive for trade openness and negative for the capital control indicator which attributes high values to heavily restricted countries.

Figure 1 plots the countries in the sample according to the sensitivity to foreign influences ${ }^{8}$. There is an obvious tendency for the countries with the better developed financial markets to be more sensitive to external influences.

\section{Figure 1 : Sensitivity of Selected World Capital Markets to Foreign Economic Influences}

We analyze quantitatively the relationship between financial development and the susceptibility of the domestic stock market to foreign influences by running the cross sectional regression

$$
z_{f, i}=\alpha+\beta^{\prime} \mathbf{F}_{i}+\gamma^{\prime} \mathbf{X}_{i}+\varepsilon_{i}
$$

where $z_{f, i}$ denotes the sensitivity measure from the VAR analysis, $F_{i}$ is the level of development of a country's financial market, $\mathbf{X}_{i}$ is a conditioning set of control variables and $\varepsilon_{i}$ is an iid residual. $\mathbf{X}_{i}$ includes a number of variables that are correlated with the level of financial development such as the existence of capital restrictions and the degree of openness. These variables can provide valuable information concerning the channels responsible for the relationship between development and susceptibility to external shocks.

Table 2 reports the results of various regressions of $z_{f, i}$ against $F_{i}$ (that is, without including $\mathbf{X}_{i}$ ) where $z_{f, i}$ is defined either as the variance contribution of the sum of all external disturbances $\left(z \_v d\right)$ or as the contribution of the foreign stock return innovations $\left(z \_v d \_s t\right)$. These values have been calculated from a VAR with six variables and two lags. The regressor $F_{i}$ in the univariate regression corresponds to $c c b, l l y, p c$ and eqv, respectively. Figure 2 displays one of these regressions. It can be seen that countries with a high degree of financial development are more sensitive to foreign economic influences ${ }^{9}$. These results hold for all different development indicators and are even stronger under the narrow definition of $z_{f, i}$. We also run multivariate regressions including simultaneously a credit market measure and the stock market measure $e q v^{10}$ (the results are very

\footnotetext{
${ }^{8}$ This plot corresponds to the VAR model with six variables and two lags. Log likelihood tests show that in most countries $\operatorname{VAR}(1)$ is too restrictive. On the other hand, we prefer a parsimonious model over richer setups because of the degrees of freedom which are likely to represent a limiting factor in countries with a smaller number of observations. Namely, we do not take into consideration a $\operatorname{VAR}(4)$ formulation and drop inflation and exchange rate, as they have repeatedly proved to be the influences with the smallest stock return effects.

${ }^{9}$ The results reported here are very robust to changes in the specification (number of variables, choice of lags, definition of the external factors, definition of the level of economic development). The number of possible combinations for a regression of the type $z_{f}=\alpha+\beta F_{i}+\varepsilon_{i}$ (that is without the control variables) is 360. A significant, positive slope is found in most of these specifications. There are two patterns worth reporting from these regressions. First, Japan seems to differ from Germany and the United States in the sense that its economic innovations do not affect financially developed countries differently from emerging markets. And second, the relationship between financial integration and financial development is stronger under the narrow measure of financial integration.

${ }^{10}$ Source: World Bank. The figures used are average values for the period 1988-1998.
} 
similar independent of the credit market measure used). An interesting feature of these regressions is that both measures of financial development matter, a finding that indicates that they represent alternative, independent channels through which financial development affects stock prices.

Table 2 : Stock Market Sensitivity to External Factors and the Degree of Financial Development

Figure 2 : $\quad$ Stock Market Sensitivity to External Factors and the Degree of Financial Development

In the theory part of the paper, we sketched two transmission channels linking financial development to financial integration. Among the factors suggested for accounting for the difference in economic sensitivity of financial markets across levels of financial development, the most obvious are capital controls and the degree of trade openness. Table 3 reports representative regressions when capital controls ${ }^{11}$ and the degree of openness (exports plus imports divided by GDP) are added as an explanatory variable.

Table 3 : $\quad$ Stock Market Sensitivity to External Factors and the Sources of Financial Development

It can be seen that the estimated coefficients of the control variables come out with the expected sign ${ }^{12}$. Interestingly, their presence does not take away the explanatory power of the level of financial development. The size and statistical significance of that variable remains unaffected by this, while the explanatory power of the regression tends to increase. This outcome is particularly pronounced when capital control is included as the additional regressor. The coefficients of financial maturity is unchanged and the estimated effect of the capital control variable is weakly significant ${ }^{13}$. The trade openness coefficient is insignificant but it does lower somewhat the significance of $l l y$ and $p c$ which both measure the size of the financial market. Including cross-products between the right-hand variables to test for multiplicative effects does not lower the influence of financial development on the susceptibility of the stock markets to foreign influences (not reported).

\footnotetext{
${ }^{11}$ We have made use of three variables proposed by Tamirisa (1999) (with data taken from IMF's Exchange Rate Arrangements and Currency Convertibility indexes for 1996): Index of Capital Controls, Index of Controls on Current Payments and Transfers, and a composite Exchange and Capital Control Indicator computed as the sum of the previous two indexes.

${ }^{12}$ It is positive for the openness and negative for the capital control indicator. The capital control measure can take on values between 0 and 1 , where 1 indicates total control and hence leads to capital immobility.

${ }^{13}$ The significance is even stronger for the Index of Current Payments and Transfers (not reported).
} 
One may therefore conclude that while financial development does not seem to influence international integration through its relationship with capital controls ${ }^{14}$ and trade openness, it does have effects through other channels. The identification of those channels (informational, quality of management of local financial institutes, institutional features and so on) represents a valuable task.

\section{Conclusions}

We have proposed a new indicator of international integration (domestic sensitivity to external factors) which relies on variance decompositions from two-country VARs. We then used this indicator in a large sample of countries for the period 1980 and 1998 in order to evaluate the hypothesis that financial development makes a country's financial (stock) markets more sensitive to foreign economic shocks. Our results, which are very robust across many specifications, indicate that this is indeed the case. Interestingly, the contribution of the level of financial development is not diminished when measures of official capital restrictions as well as the degree of trade interdependence are included in the regressions. This suggests that the influence of financial development operates through other channels (such as information, quality of management and so on) beyond the traditionally identified ones and which have not received much empirical scrutiny in the literature yet.

\footnotetext{
${ }^{14}$ Montiel and Reinhart (1999) find that the existence of capital control does not seem to influence the volume of international capital flows (but it affects its composition).
} 


\section{References}

[1] Ammer, John and Jianping Mei (1996): Measuring International Economic Linkages with Stock Market Data, Journal of Finance, vol. 51, no. 5, pp. 1743-1763.

[2] Bekaert, Geert and Campbell R. Harvey (1995): Time-Varying World Market Integration, Journal of Finance, vol. 50, no. 2, pp. 403-444.

[3] Bekaert, Geert and Campbell R. Harvey (1997): Emerging Equity Market Volatility, Journal of Financial Economics, vol. 43, no. 1, pp. 29-77.

[4] Canova, Fabio and Harris Dellas (1993): Trade Interdependence and the International Business Cycle, Journal of International Economics, vol. 34, no.1-2, pp. 23-47.

[5] Canova, Fabio and Gianni De Nicoló (1997): Stock Returns, Term Structure, Inflation and Real Activity, CEPR, no. 1614.

[6] Chow, Gregory C. and An-loh Lin (1971): "Best Linear Unbiased Interpolation, Distribution, and Extrapolation of Time Series by Related Series", Review of Economics and Statistics, vol. 53, no. 4, pp. 372-375.

[7] Cuche, Nicolas A. and Martin K. Hess (1999): Estimating Monthly GDP in a General Kalman Filter Framework: Evidence from Switzerland, Studienzentrum Gerzensee, Working Paper no. 99.02.

[8] Dellas, Harris and Martin K. Hess (2000): Financial Integration and the International Business Cycle, mimeo.

[9] Harvey, Campbell R. (1995): Predictable Risk and Returns in Emerging Markets, Review of Financial Studies, vol. 8, no. 3, pp. 773-816.

[10] Helpman, Elhanam and Assaf Razin, (1978), A Theory of International Trade under Uncertainty, Academic Press.

[11] King, Robert G. and Ross Levine (1993): Finance, Entrepreneurship, and Growth, Journal of Monetary Economics, vol. 32, no. 3, pp. 513-542.

[12] Levine, Ross, Norman Loyaza and Thorsten Beck (1999): Financial Intermediation and Growth: Causality and Causes, World Bank Policy Research Paper, no. 2059.

[13] Montiel, Peter and Carmen M. Reinhart (1999): Do Capital Controls and Macroeconomic Policies Influence the Volume and Composition of Capital Flows? Evidence from the 1990s, Journal of International Money and Finance, vol. 18, no. 4, pp. 619-635. 
[14] Razin, Assaf, Efraim Sadka and Chi-Wa Yuen (1999), Implications of the Home Bias: A Pecking Order of Capital Inflows and Corrective Taxation, in: Asaf Razin and Efraim Sadka (eds.), The Economics of Globalization, Cambridge, Cambridge University Press, pp. 85-122.

[15] Rouwenhorst, K. Geert (1999): Local Return Factors and Turnover in Emerging Stock Markets, Journal of Finance, vol. 54, no. 4, pp. 1439-1464.

[16] Tamirisa, Natalia T. (1999): Exchange and Capital Controls as Barriers to Trade, International Monetary Fund Staff Papers, vol. 46, no. 1, pp. 69-88. 


\section{Appendix}

\section{A Data}

\section{A.1 Raw Data}

\begin{tabular}{|c|c|c|c|c|c|c|}
\hline Country & GDP & Inflation & $\begin{array}{l}\text { USD ex- } \\
\text { change rate }\end{array}$ & $\begin{array}{l}\text { Short term } \\
\text { interest rate }\end{array}$ & $\begin{array}{l}\text { Stock market } \\
\text { index }\end{array}$ & Sample \\
\hline Argentina & AGGDP..8C ${ }^{1}$ & AGI64..X ${ }^{2}$ & AGI..AE. & AGI60BA. & IFCARGL & $80.1-98.4$ \\
\hline Australia & AU001000D & AUI64...F & AUI..AE. & AUSHORT $^{3}$ & TOTMKAU & $80.1-98.4$ \\
\hline Austria & OEI99B.PC & OEI64..F & OEI..AE. & OEI60B.. & TOTMKOE AS & $80.1-98.4$ \\
\hline Bangladesh & BSI99B.PC & BSI64...F & BSI..AE. & BSI60L.. & BDTALSH & $90.1-98.4^{6}$ \\
\hline Belgium & BGGDP...D BF & BGI64...F & BGI..AE. & BGI60B.. & TOTMKBG BF & $85.1-98.4$ \\
\hline Brazil & BRI99B.P & BRI64..X & BRI..AE. & BRI60K.. & IFCBRAL & $85.1-98.4$ \\
\hline Canada & CNGDP...D & CNI64..F & CNI..AE. & CNI60B...A & TOTMKCN & $80.1-98.4$ \\
\hline Chile & CLI99B.PC & CLI64..X & CLI..AE. & CLI60P.. & IFCHILL & $80.1-98.4$ \\
\hline Colombia & CBI99B.PC & CBI64..X & CBI..AE. & CBI60L.. & IFCOLBL & $86.1-97.4$ \\
\hline Denmark & DKI99B.P & DKI64..F & DKI..AE. & DKI60B.. & TOTMKDK & $80.1-98.4$ \\
\hline Finland & FNI99B.PC & FNI64...F & FNI..AE. & FNI60B.. & FNOCSPRC & $80.1-98.4$ \\
\hline France & FROCGVOLG & FRI64...F & FRI..AE. & ECFFR3M & TOTMKFR FF & $85.1-98.4$ \\
\hline Germany & BDI99B.RD & BDI64..F & BDI..AE. & BDI60B.. & TOTMKBD DM & $80.1-98.4$ \\
\hline Greece & GROCAGDP & GRI64..X & GRI..AE. & GROCOIB $\%$ & IFCGREL & $80.3-98.4$ \\
\hline Hong Kong & HKGDP ...C & HKCPHSALF & HKI..AE. & HKIBORNT & TOTMKHK & $84.1-98.4$ \\
\hline Hungary & HNGDPCNF & HNI64...F & HNI..AE. & HNDABLYM & BUXINDX & $91.1-98.4$ \\
\hline India & INI99BOPC $^{3}$ & INI64...F & INI..AE. & INI60P.. & IFCINDL & $80.1-97.4$ \\
\hline Indonesia & IDI99BOPC $^{3}$ & IDI64...F & IDI..AE. & IDIBK... & TOTMKID & $90.2-98.4$ \\
\hline Israel & ISGDP...D ${ }^{4}$ & ISI64..X & ISI..AE. & ISBORTBL & ISTGNRL & $86.3-98.4$ \\
\hline Italy & ITI99B.RD & ITI64..F & ITI..AE. & ITI60B.. & TOTMKIT L & $80.1-98.2$ \\
\hline Japan & JPI99B.RD & JPI64..F & JPI..AE. & JPI60B.. & TOTMKJP & $80.4-98.4$ \\
\hline Jordan & JOI99B.PC & JOI64...F & JOI..AE. & JOI60... & IFCJORL & $80.1-97.4$ \\
\hline Malaysia & MYI99B.P & MYI64...F & MYI..AE. & MYI60B.. & TOTMKMY & $86.1-97.4$ \\
\hline Mexico & MXGDP...C & MXI64..X & MXI..AE. & MXI60B.. & IFCMEXL & $81.2-98.4$ \\
\hline Netherlands & NLGDP...D & NLI64...F & NLI..AE. & NLI60B.. & TOTMKNL FL & $80.1-98.4$ \\
\hline New Zealand & NZI99B.RD & NZI64...F & NZI..AE. & NZIBK3M & TOTMKNZ & $88.1-98.4$ \\
\hline Nigeria & NGI99B.PC & NGI64..X & NGI..AE. & NGI60... & IFCNIGL & $84.3-98.4$ \\
\hline Norway & NWI99B.PC & NWI64..F & NWI..AE. & NWI60B.. & TOTMKNW & $80.1-98.4$ \\
\hline Pakistan & PKI99B.PC & PKI64...F & PKI..AE. & PKI60B.. & IFCPAKL & $84.4-98.4$ \\
\hline Peru & PEI99B.PC & PEI64...F & PEI..AE. & PEI60P.. & PEGENRL & $91.1-98.4$ \\
\hline Philippines & PHI99B.PC & PHI64...F & PHI..AE. & PHI60C.. & IFCPHIL & $84.4-98.4$ \\
\hline Portugal & PTI99B.P & PTI64..F & PTI..AE. & PTI60B.. & POBVLGN PE & $88.1-97.4$ \\
\hline Singapore & SPI99B.PC & SGI64...F & SGI..AE. & SPI60B.. & TOTMKSG & $85.2-98.4$ \\
\hline South Africa & SAI99B.RD & SAI64..X & SAI..AE. & SAI60B.. & TOTMKSA & $80.1-98.4$ \\
\hline South Korea & KOI99B.P & KOI64..F & KOI..AE. & KOI60B.. & IFCKORL & $82.1-98.4$ \\
\hline Spain & ESESGDP.D & ESI64..F & ESI..AE. & ESI60B.. & MADRIDI EP & $80.1-98.4$ \\
\hline Sri Lanka & LKGDP... & LKI64...F & LKI..AE. & LKIBOTPM. & SRALLSH & $85.1-97.4$ \\
\hline Sweden & SDESGDP.D & SDI64...F & SDI..AE. & SDI60B.. & TOTMKSD & $82.1-98.4$ \\
\hline Switzerland & SWI99B.RD & SWI64..F & SWI..AE. & SWI60B.. & TOTMKSW & $80.1-98.4$ \\
\hline Taiwan & TWGDP...C & TWCP....F & TAIWDUS $^{5}$ & TWTRSBL\% & TAIWGHT & $86.1-98.4$ \\
\hline Thailand & THI99B.PC & THI64...F & THI..AE. & THI60B.. & IFCTHAL & $86.1-97.4$ \\
\hline Turkey & TKI99B.PC & TKI64..X & TKI..AE. & TKOCOIBRF & IFCTURL & $87.1-98.4$ \\
\hline United Kingdom & UKI99B.RD & UKI64..F & UKI..AE. & UKI60B.. & TOTMKUK & $80.1-98.4$ \\
\hline United States & USI99B.RD & USI64..F & USI..AE. & USI60B.. & TOTMKUS & $80.1-98.4$ \\
\hline Venezuela & VEGDPCON & VEI64..X & VEI..AE. & VEI60L.. & IFCVENL & $85.1-98.4$ \\
\hline
\end{tabular}

Notes:

${ }^{1}$ Source: Datastream. Tables contain Datastream mnemonics.

${ }^{2}$ High inflation countries are denoted with mnemonic extension X indicating annual CPI changes which we decompose into quarterly inflation rates. For all other countries, inflation calculation is standard.

${ }^{3}$ The series IDI99BOPC, INI99BOPC are discontinued in 1992.4 and AUSHORT in 1980.4. They are completed with IDI99B.PC, INI99B.PC and AUSTB3M, respectively.

${ }^{4}$ Data after 1997.3 from Central Bureau of Statistics of Israel.

${ }^{5}$ Inverse value.

${ }^{6}$ Due to an insufficient number of observations, VAR's cannot be reliably estimated for Hungary, Indonesia and Peru, and are therefore omitted. 


\section{A.2 Data Computation}

GDP growth, stock returns and, where calculated, inflation are discrete time values computed as

$$
r_{t}=\frac{p_{t}-p_{t-1}}{p_{t-1}} \cdot 100
$$

where $p_{t}$ represents the respective values in levels. Due to imprecise consumer price indexes in high inflation countries, we recursively calculate quarterly percentage CPI changes $\pi$ from available annual observations $\pi^{a}$.

$$
\pi_{t}=\left(\left(\frac{1+\pi_{t+3}^{a} / 100}{1+\pi_{t+4}^{a} / 100}\right)\left(1+\pi_{t+4} / 100\right)-1\right) \cdot 100
$$

Note that we need the last four quarterly inflation rates $\pi_{T}, \ldots, \pi_{T-3}$ of the series. We calculate them in the standard manner.

Real returns are calculated as

$$
R_{t}=\frac{\left(1+r_{t} / 100\right)}{\left(1+\pi_{t} / 100\right)} \cdot 100 .
$$

We use interest and exchange rates in levels. DEM and GBP exchange rates are calculated via the cross rates with USD.

Where necessary, seasonal adjustments are made to level data with the X11 multiplicative method by the U.S. Bureau of Census, including the related series for the interpolation. The additive method applies to the recursively calculated inflation rates because of possible negative values.

\section{A.3 Modeling Quarterly GDP}

\section{A.3.1 Model}

In order to have a sufficient number of observations for the VAR we need quarterly data. As in most developing countries GDP is published yearly, we decompose annual values in to four quarterly estimates. In a wide range of Kalman Filter models for interpolation, Cuche and Hess (1999) identify a static setup with related series based on Chow and Lin (1971) as the most suitable one for the decomposition of published GDP estimates for Switzerland into higher frequency.

In the state equation

$$
\left(\begin{array}{c}
y_{t+1} \\
y_{t} \\
y_{t-1} \\
y_{t-2}
\end{array}\right)=\left(\begin{array}{cccc}
0 & 0 & 0 & 0 \\
1 & 0 & 0 & 0 \\
0 & 1 & 0 & 0 \\
0 & 0 & 1 & 0
\end{array}\right)\left(\begin{array}{c}
y_{t} \\
y_{t-1} \\
y_{t-2} \\
y_{t-3}
\end{array}\right)+\left(\begin{array}{cccc}
c_{1} & c_{2} & \ldots & c_{w} \\
0 & 0 & \ldots & 0 \\
0 & 0 & \ldots & 0 \\
0 & 0 & \ldots & 0
\end{array}\right)\left(\begin{array}{c}
x_{t+1}^{1} \\
x_{t+1}^{2} \\
\vdots \\
x_{t+1}^{w}
\end{array}\right)+\left(\begin{array}{c}
u_{t+1} \\
0 \\
0 \\
0
\end{array}\right)
$$


$y_{t+1}$ represents the monthly estimate, $x_{t+1}^{i}$ the $i$-th related series and $u_{t+1}$ an iid residual. The observation equation of the state space system ensures that the interpolated quarterly estimates sum up to the annual value $y_{t}^{+15}$ :

$$
\begin{aligned}
y_{t}^{+} & =\mathbf{h}_{t}^{\prime} \cdot\left(\begin{array}{llll}
y_{t} & y_{t-1} & y_{t-2} & y_{t-3}
\end{array}\right)^{\prime} \\
\text { where } \mathbf{h}_{t}^{\prime} & =\left(\begin{array}{llll}
0 & 0 & 0 & 0
\end{array}\right), \text { for } t=1,2,3,5,6,7 \ldots, T-1, \\
\text { and } \mathbf{h}_{t}^{\prime} & =\left(\begin{array}{llll}
1 & 1 & 1 & 1
\end{array}\right), \text { for } t=4,8,12, \ldots, T .
\end{aligned}
$$

\section{A.3.2 Interpolated Series}

We interpolate annual GDP to quarterly estimates for the following countries and extract information from related series at a quarterly frequency:

\begin{tabular}{ll} 
Country & Related Series \\
\hline Bangladesh & BSI66...F \\
Brazil & BRINPRODH \\
Colombia & CBI66AA.F \\
Greece & GRI66..IF \\
India & INI66..F \\
Jordan & JOI66...F \\
Malaysia & MYI66..F \\
Nigeria & NGI66EY.F \\
Pakistan & PKI72...F and PKI73...F \\
Sri Lanka & LKTNATOTP \\
Thailand & THMINOILP and THMINIRNP \\
Venezuela & VEPETRLPF \\
\hline & \\
& \\
Notes: & \\
${ }^{1}$ Source: Datastream. Tables contain Datastream mnemonics.
\end{tabular}

\footnotetext{
${ }^{15}$ In all the models, annual GDP $y_{t}^{+}$is reported quarterly and its values for the first three quarters of the year are set to zero.
} 
Table 1: Statistical Properties of the Data

Panel A: Summary Statistics of Various Measures ${ }^{1}$

\begin{tabular}{rrrrrrrrr} 
& \multicolumn{4}{c}{ Sensitivity $^{2}$} & \multicolumn{3}{c}{ Development $^{3}$} & \multicolumn{3}{c}{ Control $^{4}$} \\
& $z \_v d$ & $z \_v d \_s t$ & $c c b$ & \multicolumn{1}{c}{$l l y$} & \multicolumn{1}{c}{$p c$} & \multicolumn{1}{c}{$e q v$} & \multicolumn{1}{c}{$k c i$} & \multicolumn{1}{c}{ op } \\
\hline Mean & 33.42 & 18.10 & 88.62 & 60.17 & 67.78 & 2314.96 & 0.35 & 69.68 \\
Median & 27.29 & 14.52 & 92.29 & 56.63 & 68.22 & 1282.52 & 0.30 & 56.14 \\
Max. & 73.90 & 55.18 & 99.75 & 169.64 & 176.12 & 11101.38 & 0.91 & 371.91 \\
Min. & 10.20 & 0.82 & 63.34 & 14.03 & 9.78 & 11.37 & 0.01 & 15.18 \\
S.D. & 17.68 & 14.29 & 10.86 & 32.28 & 40.40 & 2626.66 & 0.27 & 62.36 \\
\hline
\end{tabular}

Panel B: Correlations between Development Measures

\begin{tabular}{rrrrrrr} 
& \multicolumn{1}{c}{$c c b$} & \multicolumn{1}{l}{$l l y$} & \multicolumn{1}{l}{ pc } & \multicolumn{1}{c}{ eqv } & $k c i$ & \multicolumn{1}{l}{$o p$} \\
\hline$c c b$ & 1 & & & & & \\
$l l y$ & 0.55 & 1 & & & & \\
$p c$ & 0.66 & 0.83 & 1 & & & \\
$e q v$ & 0.47 & 0.62 & 0.74 & 1 & & \\
$k c i$ & -0.39 & -0.26 & -0.28 & -0.01 & 1 & \\
$o p$ & 0.46 & 0.24 & 0.15 & 0.29 & 0.07 & 1 \\
\hline
\end{tabular}

Notes:

${ }^{1}$ The following countries are included: Argentina, Australia, Austria, Bangladesh, Belgium, Brazil, Canada, Chile, Colombia, Denmark, Finland, France, Germany, Greece, Hong Kong, India, Israel, Italy, Japan, Jordan, Korea, Rep. of, Malaysia, Mexico, Netherlands, New Zealand, Nigeria, Norway, Pakistan, Philippines, Portugal, Singapore, South Africa, Spain, Sri Lanka, Sweden, Switzerland, Taiwan, Thailand, Turkey, United Kingdom, United States, Venezuela. Various other countries were excluded for insufficient numbers of observations. ${ }^{2}$ Sensitivity indicators are measured by the influence of innovations as measured by the variance decomposition of a VAR with a 6-variable vector. $z_{-} v d$ includes the impact of all foreign economic variables, $z_{-} v d_{-} s t$ includes foreign stock returns. Percentage values calculated 1980.1-1998.4 or for the maximum numbers of observations for countries with a smaller available sample. The correlation between $z_{-} v d$ and $z_{-} v d_{-} s t$ is 0.83 . 3 ccb: commercial bank assets/ total bank assets, lly: liquid liabilities/GDP, pc: private credit/GDP, eqv: stock market value/GDP. Country figures are averaged percentage values 1980.1-1995.4 (1988.1-1998.4 for eqv).

${ }_{k c i}$ : capital control indicator in 1996, op: trade openness measure 1980.1-1995.4. 
Table 2: Stock Market Sensitivity to External Factors and the Degree of Financial Development

\begin{tabular}{cccccccc}
$z_{f}$ & $F_{i}^{1}$ & $\beta$ & $t$ & $F_{i}^{2}$ & $\beta$ & $t$ & $a d j . R^{2}$ \\
\hline$z \_v d$ & $c c b$ & $0.73^{* *}$ & 3.02 & & & & 0.21 \\
& $l l y$ & $0.23^{* *}$ & 2.21 & & & & 0.11 \\
& $p c$ & $0.19^{* *}$ & 2.40 & & & & 0.13 \\
& $e q v$ & 0.06 & 0.59 & & & & -0.01 \\
\multirow{5}{*}{ z_vd_st } & $c c b$ & $0.77^{* *}$ & 2.84 & $e q v$ & 0.12 & 0.25 & 0.23 \\
& $c c b$ & $0.71^{* *}$ & 3.63 & & & & 0.28 \\
& $l l y$ & $0.27^{* *}$ & 3.35 & & & & 0.22 \\
& $p c$ & $0.24^{* *}$ & 4.00 & & & & 0.33 \\
& $e q v$ & $0.16^{*}$ & 1.95 & & & & 0.06 \\
& $c c b$ & $0.19^{* *}$ & 5.10 & $e q v$ & $0.18^{*}$ & 1.82 & 0.24 \\
\hline
\end{tabular}

Notes:

${ }^{1}$ Sensitivity indicators are measured by the influence of innovations as measured by the variance decomposition of a VAR with a 6 -variable vector. $z_{-} v d$ includes the impact of all foreign disturbances, $z_{-} v d_{-} s t$ includes foreign stock returns.

2 ccb: commercial bank assets/total bank assets, lly: liquid liabilities/GDP, $p c$ : private credit/GDP, eqv: stock market value/GDP.

3 Significance level: ${ }^{*}=90 \%,{ }^{* *}=95 \%$ level. 
Table 3: Stock Market Sensitivity to External Factors and the Sources of Financial Development

\begin{tabular}{|c|c|c|c|c|c|c|c|}
\hline$z_{f}$ & $F_{i}$ & $X_{i}$ & $\beta$ & $t$ & $\gamma$ & $t$ & $\operatorname{adj} . R^{2}$ \\
\hline \multirow[t]{4}{*}{$z \_v d$} & $c c b$ & $k c i$ & $0.69^{* *}$ & 2.94 & -12.09 & -1.19 & 0.30 \\
\hline & $l l y$ & $k c i$ & $0.35^{* *}$ & 3.71 & -14.41 & -1.58 & 0.39 \\
\hline & $p c$ & $k c i$ & $0.24^{* *}$ & 3.57 & -15.51 & -1.69 & 0.38 \\
\hline & $e q v$ & $k c i$ & 0.08 & 0.80 & $-18.50^{*}$ & -1.89 & 0.07 \\
\hline \multirow[t]{4}{*}{$z \_v d \_s t$} & $c c b$ & $k c i$ & $0.66^{* *}$ & 3.09 & -11.57 & -1.27 & 0.33 \\
\hline & $l l y$ & $k c i$ & $0.34^{* *}$ & 4.19 & -13.48 & -1.69 & 0.45 \\
\hline & $p c$ & $k c i$ & $0.26^{* *}$ & 4.44 & $-14.16^{*}$ & -1.83 & 0.48 \\
\hline & $e q v$ & $k c i$ & 0.13 & 1.64 & $-20.99^{*}$ & -2.61 & 0.20 \\
\hline \multirow[t]{4}{*}{$z \_v d$} & $c c b$ & $o p$ & $0.63^{* *}$ & 2.21 & 0.12 & 1.13 & 0.26 \\
\hline & $l l y$ & $o p$ & 0.19 & 1.56 & 0.14 & 1.42 & 0.20 \\
\hline & $p c$ & $o p$ & $0.14^{*}$ & 1.68 & 0.18 & 1.73 & 0.21 \\
\hline & $e q v$ & op & -0.00 & -0.02 & 0.06 & 1.12 & -0.01 \\
\hline \multirow[t]{4}{*}{$z \_v d_{-} s t$} & $c c b$ & $o p$ & $0.67^{* *}$ & 2.81 & 0.06 & 0.68 & 0.30 \\
\hline & $l l y$ & $o p$ & $0.28^{* *}$ & 2.79 & 0.07 & 0.73 & 0.30 \\
\hline & $p c$ & $o p$ & $0.21^{* *}$ & 3.02 & 0.08 & 0.92 & 0.30 \\
\hline & $e q v$ & $o p$ & 0.14 & 1.48 & 0.02 & 0.46 & 0.04 \\
\hline \multirow[t]{2}{*}{$z \_v d$} & - & $k c i$ & - & - & $-20.02^{* *}$ & -2.09 & 0.08 \\
\hline & - & $o p$ & - & - & 0.05 & 1.28 & 0.02 \\
\hline \multirow[t]{2}{*}{$z \_v d_{-} s t$} & - & $k c i$ & - & - & $-23.55^{* *}$ & -2.92 & 0.17 \\
\hline & - & $o p$ & - & - & 0.05 & 1.32 & 0.02 \\
\hline
\end{tabular}

Notes:

${ }^{1}$ Sensitivity indicators are measured by the influence of innovations as measured by the variance decomposition of a VAR with a 6 -variable vector. $z_{-} v d$ includes the impact of all foreign economic variables, $z_{-} v d_{-}$st includes foreign stock returns.

$2 c c b$ : commercial vs. central bank assets, lly: liquid liabilities/GDP, $p c$ : private credit/GDP, eqv: stock market value/GDP.

$3_{k c i}$ : capital control indicator, op: trade openness measure.

4 Significance level: ${ }^{*}=90 \%,{ }^{* *}=95 \%$ level. 


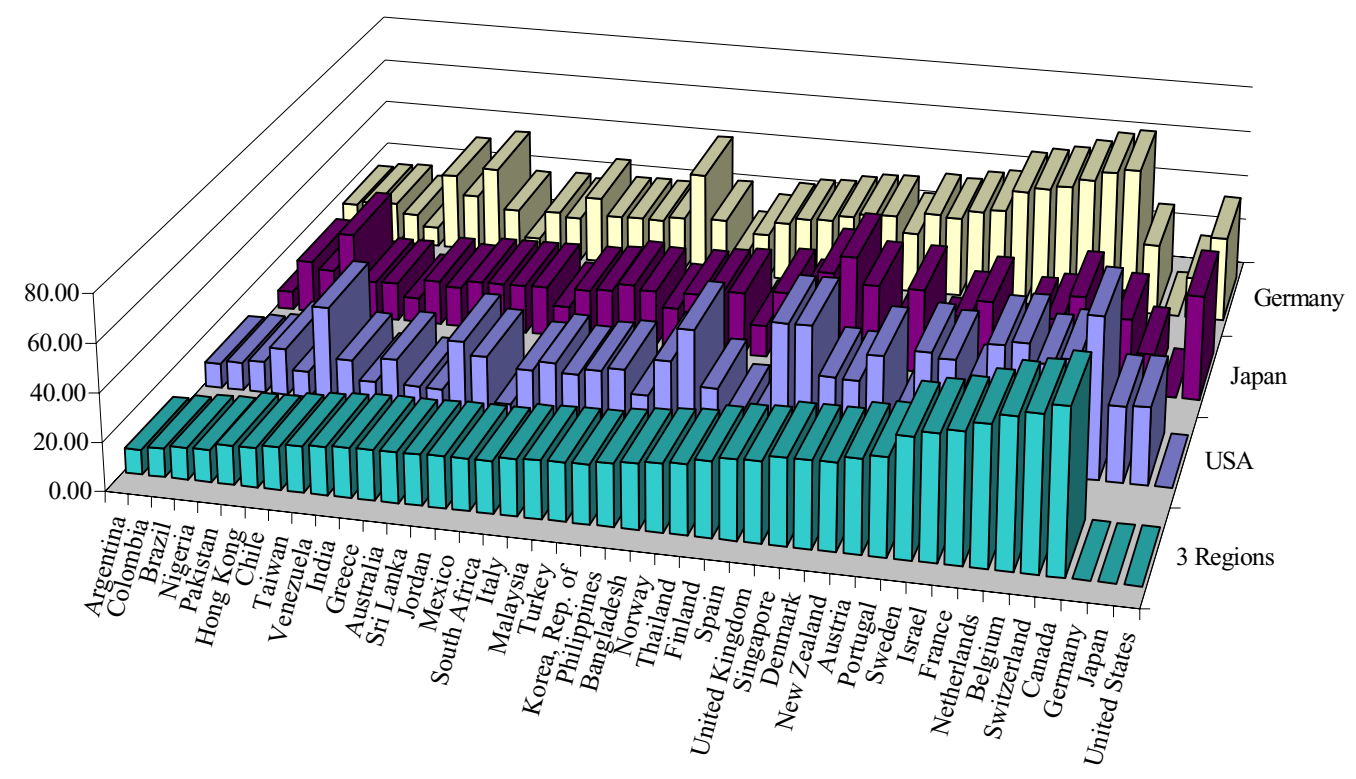

Figure 1: Sensitivity of Selected World Capital Markets to Foreign Economic Influences 


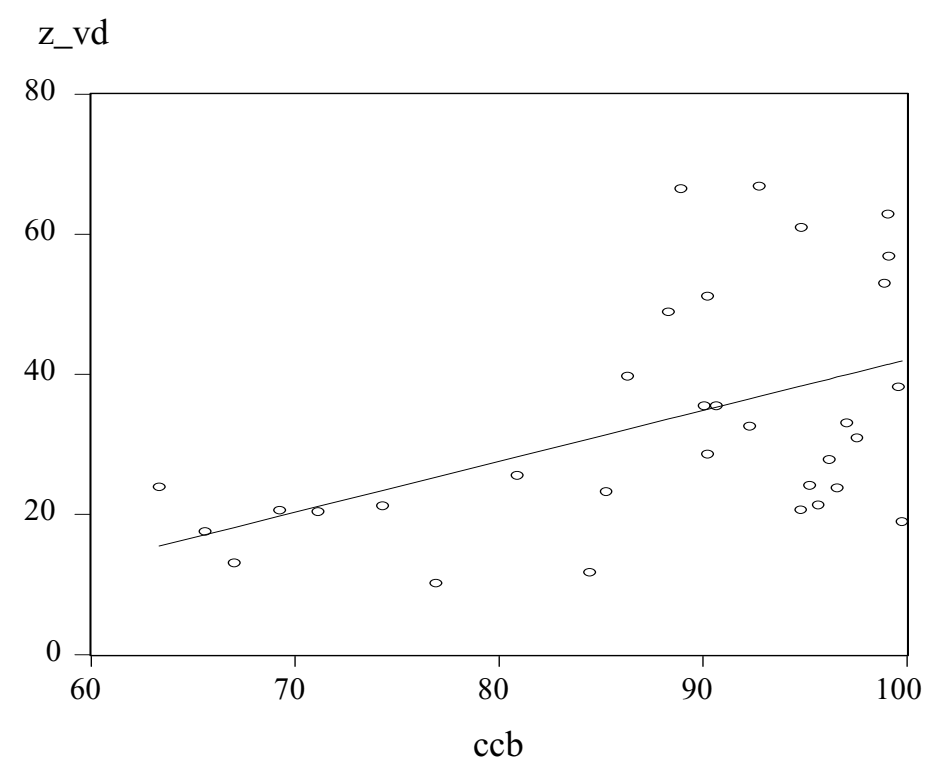

Figure 2: Stock Market Sensitivity to External Factors and the Degree of Financial Development 